\title{
Mating activates androgen receptor-containing neurons in chemosensory pathways of the male Syrian hamster brain*
}

\author{
R.I. Wood and S.W. Newman \\ Reproductive Sciences Program, Department of Anatomy and Cell Biology, University of Michigan, Ann Arbor, MI 48109-0616 (USA)
}

(Accepted 12 January 1993)

Key words: Androgen receptor; c-fos; Sexual behavior; Amygdala; Immunocytochemistry; Limbic system

\begin{abstract}
Fos-immunoreactivity is induced during mating in the male Syrian hamster in limbic areas that relay chemosensory information and contain receptors for gonadal steroid hormones. The induction of Fos is an index of neuronal activation. After mating, c-fos expression is greatest in subnuclei of the medial amygdaloid nucleus (Me), bed nucleus of the stria terminalis (BNST), and medial preoptic area (MPOA). The present study determined if individual neurons in these activated subnuclei contain androgen receptors. We aim to understand how essential chemosensory and hormonal signals are integrated to control copulation Adult male hamsters $(n=6)$ were allowed to mate with a sexually receptive female for $30 \mathrm{~min}$. They were perfused $1 \mathrm{~h}$ later with $4 \%$ paraformaldehyde and $40 \mu \mathrm{m}$ frozen sections were processed for immunocytochemistry using antisera against Fos (Cambridge Research Biochemicals) and the androgen receptor (G.S. Prins). The brains of three non-mated males were also processed for Fos immunocytochemistry. Mating significantly increased the number of Fos-immunoreactive neurons within subnuclei of Me, BNST, and MPOA relative to non-mated males $(P<0.05)$. These nuclei contained abundant androgen receptors. In the corticomedial amygdala, 20-40\% of Fos-immunoreactive neurons in mated hamsters expressed androgen receptors. Although few androgen receptors are found in the anteromedial and postero-intermediate subdivisions of the BNST, these areas exhibited $26 \%$ and $47 \%$ co-localization, respectively. In posteromedial BNST, which contains large numbers of steroid receptor-containing neurons, androgen receptors were identified in $48 \%$ of Fos-immunoreactive neurons. In the MPOA, $54 \%$ of Fos-immunoreactive neurons expressed the androgen receptor throughout the rostrocaudal extent of the medial preoptic nucleus (MPN). The largest percentage of co-localized Fos neurons (70\%) was found in the magnocellular subdivision of MPN. These results provide the first direct evidence that androgen receptor neurons are activated by mating behavior, suggesting that such neurons may be incorporated in the neural circuitry underlying copulation. Further, they show that mating selectively and differentially activates androgen receptor cells.
\end{abstract}

\section{INTRODUCTION}

The central nervous system is a major target for steroid hormones secreted by the gonads; many aspects of behavior and neuroendocrine function are influenced by gonadal steroids, and the receptors for androgens and estrogens are widely but selectively distributed in the brain and spinal cord ${ }^{9,43,44,46,49}$. Mating behavior in the male Syrian hamster, as in many species (reviewed in ref. 3), requires the continued presence of testicular steroids. Copulation gradually declines following castration or testicular regression induced by short daylengths ${ }^{33}$. However, it is difficult to identify which groups of steroid receptor-containing neurons mediate the effects of testicular steroids on mating behavior due to the broad distribution of these receptors within the brain. To examine this question, the present study used the pattern of Fos immunoreactivity to identify populations of steroid receptor-containing neurons in chemosensory pathways that are activated during mating in the male Syrian hamster.

The medial preoptic area (MPOA) is critical for male mating behavior in a wide variety of species (see ref. 40 for review). Likewise, this area contains abundant steroid receptors. In the male hamster, MPOA lesions eliminate mating ${ }^{37}$, and central implants of testosterone into the MPOA restore sexual behavior in castrated males ${ }^{27}$. However, the MPOA is not solely

Correspondence: R.I. Wood, Department of Anatomy and Cell Biology, Medical Sciences II Building, University of Michigan, Ann Arbor, MI 48109-0616, USA. Fax: (1) (313) 763-1166.

* Preliminary reports of this work were presented at the 22nd Annual Meeting of the Society for Neuroscience, Anaheim, CA, 1992. 
A

: $: \div$

64

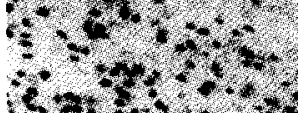

tr.

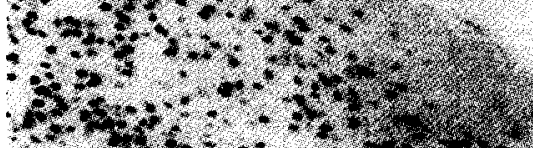

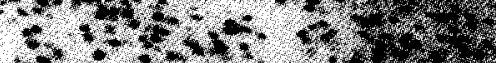

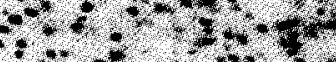

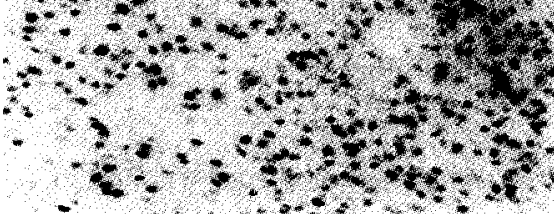

B

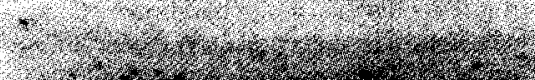

1.r.7ry

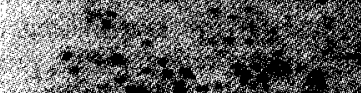

7. 0

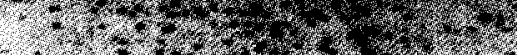

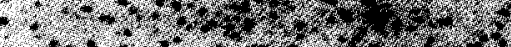

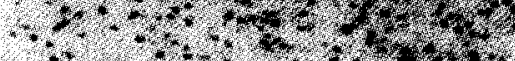

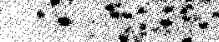

-

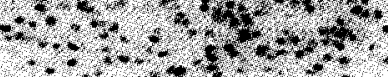
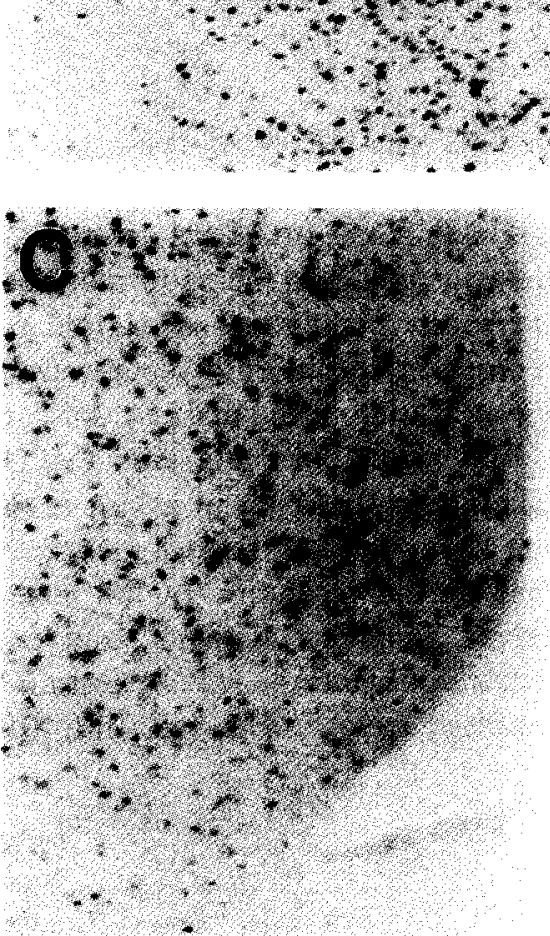

D

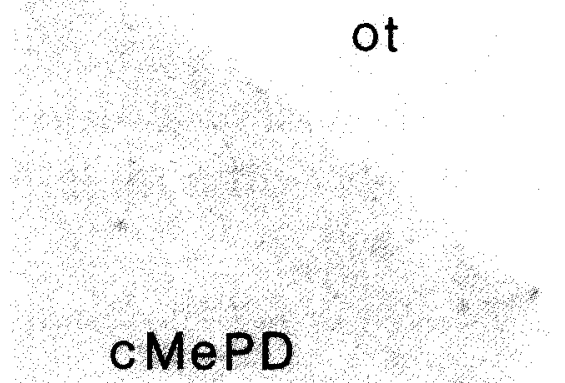

E

BNSTI

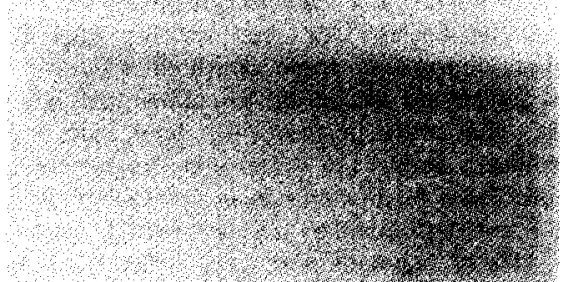

- 5 .

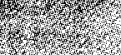

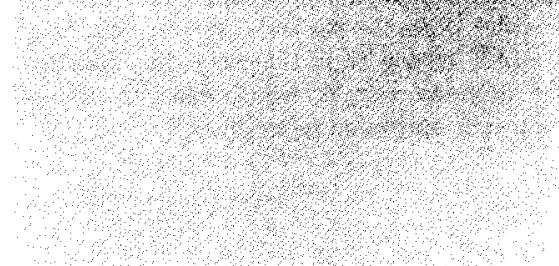


responsible for copulation in this species; the male Syrian hamster requires both chemosensory and hormonal stimuli. Whereas steroid hormones provide a long-term permissive signal for sexual behavior ${ }^{33}$, chemosensory input is required acutely for copulation ${ }^{34}$. The neural pathways for transmission of chemosensory information from the olfactory and vomeronasal systems to the MPOA have been described in detail (see ref. 40 for review). Briefly, chemosensory input via the main and accessory olfactory bulbs is transmitted along the lateral olfactory tract to the medial amygdaloid nucleus (Me). The MPOA receives projections directly from $\mathrm{Me}$, as well as indirectly through the bed nucleus of the stria terminalis (BNST). Like castration, blocking the relay of chemosensory signals by lesions along this pathway eliminates mating behavior ${ }^{25,26,37}$.

Because the MPOA, BNST, and Me transmit chemosensory information critical to the expression of sexual behavior, and because these nuclei contain large numbers of neurons that contain receptors for gonadal steroids ${ }^{12,24,49}$, we hypothesized that androgen receptor-containing neurons in MPOA, BNST, and Me would be activated during mating. Induction of Fos, a protein product of immediate-early gene activation $^{19,31,41}$, was used as a marker of neuronal activation in mated hamsters, and the activation of androgen receptor-containing neurons was compared after mating in different subnuclei of the amygdala, BNST, and MPOA.

\section{MATERIALS AND METHODS}

\section{General methods}

Nine adult male hamsters (Mesocricetus auratus) weighing between 90 and $112 \mathrm{~g}$ were purchased from Charles River Laboratories. They were housed in groups of 3-6 per cage under a long day photoperiod (14 h light/day). Food and water were provided ad libitum.

Six males were allowed to mate with a receptive female for $0.5 \mathrm{~h}$, and were perfused $1 \mathrm{~h}$ later. Mating tests were conducted during the first $4 \mathrm{~h}$ of the dark phase under dim light. During the 30 min mating test, all males displayed mounts, intromissions, and at least two ejaculations. Stimulus females were ovariectomized via dorsal incision under sodium pentobarbital anesthesia $(65 \mathrm{mg} / \mathrm{kg}$ ), and implanted s.c. with a Silastic capsule (id, $1.98 \mathrm{~mm}$; od, $3.18 \mathrm{~mm}$; Dow Corning, MI) containing a 4-mm packed column of estradiol-17B (Sigma Chemical Co., St. Louis, MO) and sealed with Silastic Adhesive A (Dow Corning). To induce lordosis, each female received 350 $\mu \mathrm{g}$ progesterone $(2.5 \mathrm{mg} / \mathrm{ml}$ in sesame oil; Sigma) i.p. $4 \mathrm{~h}$ before the first mating test. To verify basal c-fos expression, three additional males were perfused without prior contact with a female. To control for non-specific effects of handling, these males were placed for 30 $\min$ in an empty cage $1 \mathrm{~h}$ before perfusion.

For perfusion, hamsters were deeply anesthetized with sodium pentobarbital $(130 \mathrm{mg} / \mathrm{kg})$, and perfused through the aorta with 150 $\mathrm{ml}$ of $0.1 \mathrm{M}$ sodium phosphate-buffered saline containing $0.1 \%$ sodium nitrite for vasodilation, followed by $250 \mathrm{ml}$ of $0.1 \mathrm{M}$ sodium phosphate buffer $(\mathrm{PB})$ containing $4 \%$ paraformaldehyde. Brains were removed and post-fixed for $1 \mathrm{~h}$ at room temperature and then cryoprotected overnight in PB with $20 \%$ sucrose at $4^{\circ} \mathrm{C} .40-\mu \mathrm{m}$ coronal brain sections were cut on a freezing microtome, and collected into PB with $0.1 \%$ sodium azide as a preservative. Sections were stored at $4^{\circ} \mathrm{C}$ until processed for immunocytochemistry.

\section{Immunocytochemistry}

Primary antisera. To demonstrate androgen receptor immunoreactivity, we used a polyclonal rabbit antibody $(0.5 \mu \mathrm{g} / \mathrm{ml}$ in PB with $0.3 \%$ Triton X-100; gift of Dr. Gail S. Prins, University of Illinois-Chicago) directed against a synthetic peptide corresponding to the first 21 amino acids of the rat androgen receptor ${ }^{6,28}$. Fig. 1 illustrates representative androgen receptor immunostaining in Me, BNST, and MPOA. Details of the isolation and characterization of this antibody are described in Prins et al. ${ }^{38}$. Omission of primary antiserum eliminated nuclear staining (Fig. 1), as did preincubation with a $10 \times$ molar excess of the peptide antigen (Fig. 1). However, because the antibody is directed against only a fragment of the native receptor, preincubation of the primary antiserum with a synthetic peptide corresponding to a distant portion of the androgen receptor (amino acids 468-482) did not block immunostaining (Fig. 1).

Fos immunoreactivity was demonstrated using a sheep anti-Fos antibody supplied by Cambridge Research Biochemicals (Valley Stream, NY; lot \#OA-11-823), diluted $1: 1,000$ in PB with $0.3 \%$ Triton X-100. Fig. 2 presents photomicrographs of immunostaining in Me, BNST, and MPOA of mated and control males. This antibody has been previously validated for use in hamsters ${ }^{13}$ and rats ${ }^{1}$. Both Fos and androgen receptor immunoreactivity were confined to the cell nucleus.

Tissue processing. For single-label immunocytochemistry, free-floating sections were washed $3 \times$ for $5 \mathrm{~min}$ in buffer, and incubated in primary antiserum with $4 \%$ normal donkey serum for $48 \mathrm{~h}$ at $4^{\circ} \mathrm{C}$. Sections were washed, and transferred to a biotinylated secondary antibody (donkey anti-rabbit IgG or donkey anti-sheep IgG, 1:200; Jackson Immunoresearch Labs) for $1 \mathrm{~h}$ at room temperature. Sections were again rinsed, then incubated in the avidin-biotin horseradish peroxidase (HRP) complex (Vectastain ABC Elite kit, Vector Laboratories) for $1 \mathrm{~h}$. HRP was visualized using nickel chloride-enhanced $3,3^{\prime}$ diaminobenzidine (DAB) as the chromagen. Sections were mounted onto gelatin-coated slides, dehydrated in alcohols and xylenes, and coverslipped with Permount.

For double-label immunocytochemistry, the fluorescent markers FITC (fluoresceinisothyocyanate) and RITC (rhodamineisothyocyanate) were used. Fig. 3 presents photomicrographs of neurons immunostained with FITC to localize Fos immunoreactivity and with RITC for androgen receptors. For this procedure, every 4 th section was incubated in a mixture of both primary antibodies, rinsed, and exposed simultaneously to donkey anti-rabbit IgG coupled to RITC $(1: 50)$ for visualization of androgen receptors and donkey anti-sheep IgG conjugated to FITC $(1: 50)$ for detection of Fos-immunoreactive neurons. To enhance the fluorescent immunostaining, these sections were exposed to unlabelled sheep and rabbit $\lg G(1: 1,000)$, and then to additional fluorescent secondary antibodies. Sections were mounted onto slides and coverslipped with glycerol-phosphate buffer

Fig. 1. Left: photomicrographs of androgen receptor-immunoreactive neurons in a representative male hamster at the level of the posterodorsal subdivision of the medial amygdaloid nucleus (top), posteromedial BNST (middle), and medial preoptic nucleus (bottom). Right: omission of the primary antiserum prevented immunostaining (top), as did preincubation with a $10 \times$ molar excess of the peptide antigen (amino acids $1-21$, middle). However, preincubation of the primary antiserum with a synthetic peptide corresponding to amino acids $468-482$ did not eliminate immunostaining (bottom). Bar $=100 \mu \mathrm{m}$. 

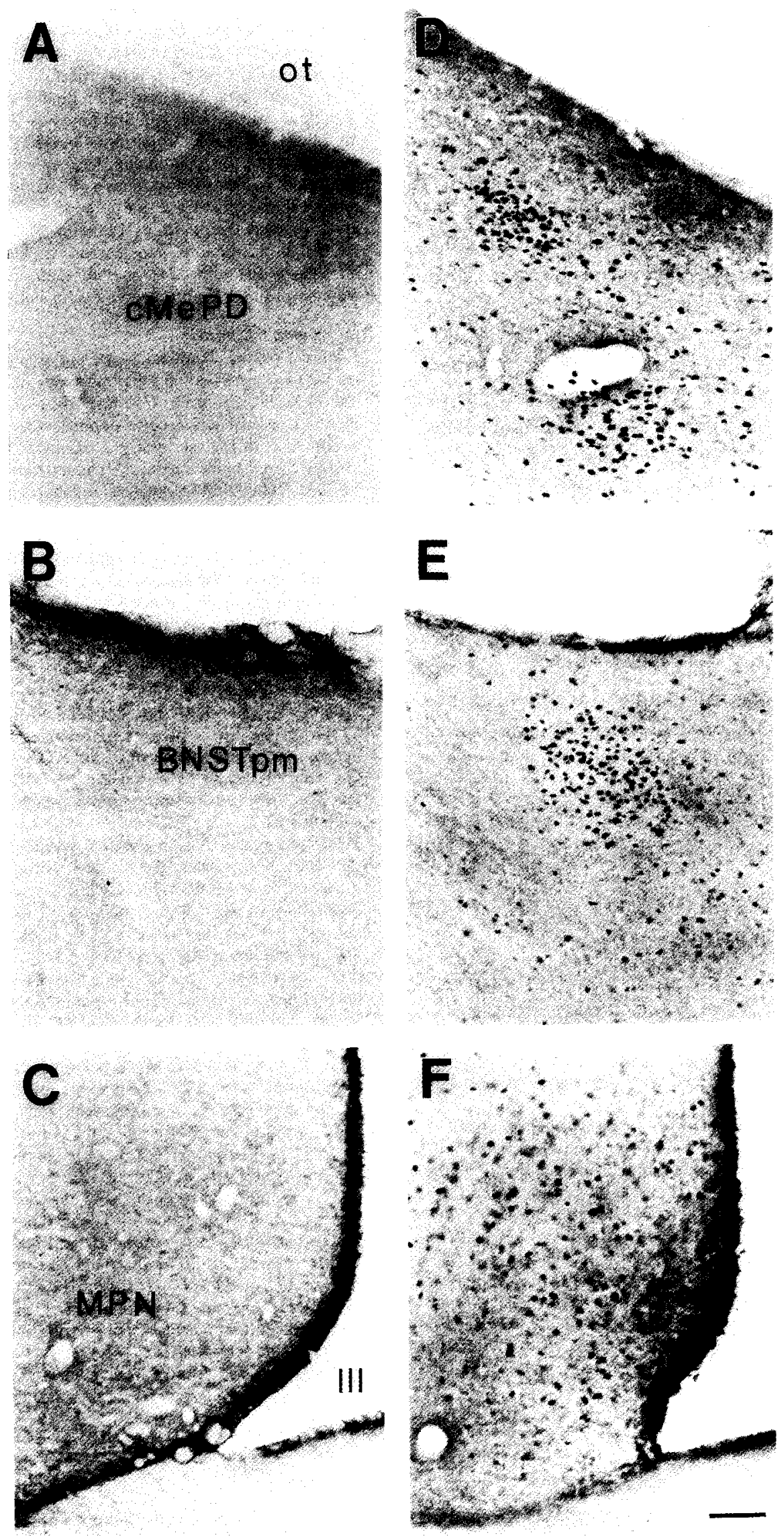

Fig. 2. Photomicrographs of Fos-immunoreactive neurons in a representative control male (left) and in a male hamster allowed to mate for 30 min (right) at the level of the posterodorsal subdivision of the medial amygdaloid nucleus (top), posteromedial BNST (middle), and medial preoptic nucleus (bottom). Bar $=100 \mu \mathrm{m}$ 
containing phenylenediamine for preservation of FITC immunofluoresence ${ }^{35}$. Fluorescent staining was visualized using a Leitz Orthoplan microscope, using an 12 filter ( $495 \mathrm{~nm}$ blue light excitation) inducing green-blue emission from FITC, and an N2 filter (525 $\mathrm{nm}$ green light excitation) inducing red emission from RITC.

\section{Data analysis}

For single-labelled Fos and androgen receptor neurons, immunostained nuclei were plotted through a drawing tube attached to a Leitz Dialux microscope onto a series of standard sections through Me, BNST, and MPOA using cresyl violet-stained sections as a guide. For androgen receptor/Fos co-localization, we verified that the pattern of immunostaining using fluorescent markers resembled that of single-labelled sections stained with DAB. To estimate the number of Fos-immunoreactive neurons containing androgen receptors in 17 different subnuclei of the amygdala, BNST, MPOA, and septum, the average number of single- and double-labelled Fos-im- munoreactive neurons within a $0.045 \mathrm{~mm}^{2}$ area was determined three times within each subnucleus for every brain. The number of Fos-immunoreactive neurons in control and mated males was compared in subnuclei of the amygdala and BNST/MPOA using a two-way analysis of variance (ANOVA) followed by post-hoc comparison with the Scheffe $F$-test. The extent of co-localization in different subnuclei was likewise compared using ANOVA. For all analyses, $P<0.05$ was considered significant.

\section{RESULTS}

Androgen receptor immunoreactivity

Fig. 1 presents photomicrographs of androgen receptor immunoreactivity in Me, BNST, and MPOA; Figs. 4 and 5 illustrate the distribution of androgen
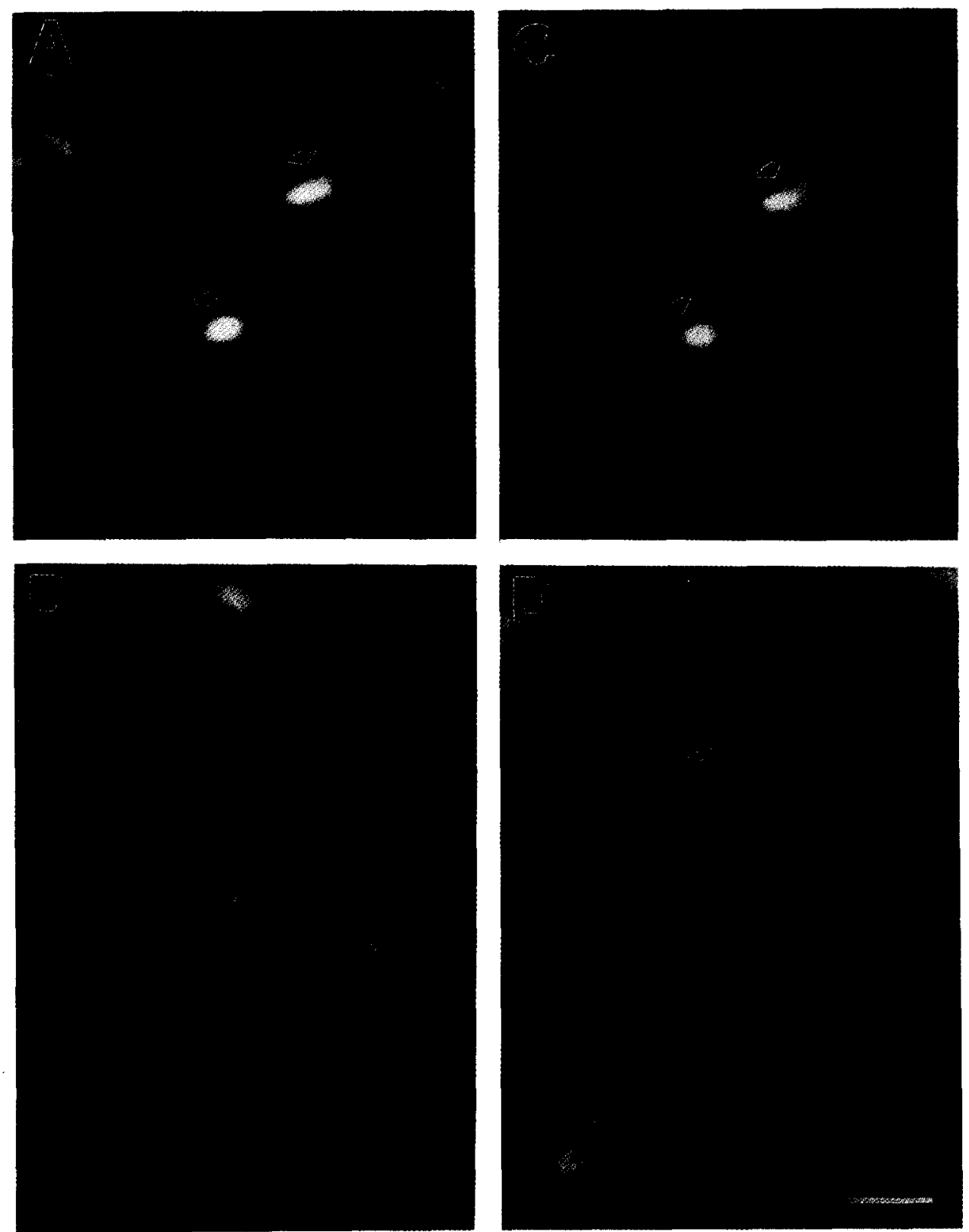

Fig. 3. Photomicrographs showing RITC-fluorescence of androgen receptor immunoreactivity (left) and FITC-fluorescence of Fos immunoreactivity (right) in the same section of the BNST from a representative male hamster. Arrows indicate neurons immunoreactive for both Fos and androgen receptors, while the arrowheads identify neurons labelled for only a single antigen. Bar $=20 \mu \mathrm{m}$. 
receptors in these areas. The location of androgen receptors in these three regions, as well as in other areas of the brain (data not shown) agreed well with previous reports of androgen receptor distribution in the hamster brain determined using steroid autoradiography ${ }^{12,49}$. In general, large numbers of steroid receptors were present in Me, BNST, and MPOA, as well as in the ventrolateral septum (LSv), and the ventromedial and arcuate nuclei of the hypothalamus. However, within all of these nuclear areas, androgen receptor-containing neurons were more abundant using immunocytochemistry as compared with earlier studies using steroid autoradiography. Mating did not alter the anatomical distribution of androgen receptor immunoreactivity.

In the amygdala (Fig. 4), the majority of androgen receptors were confined to $\mathrm{Me}$, the rostral part of the posteromedial cortical nucleus (PMCo, Fig. 4E), and amygdalohippocampal area (AHA, Fig. 4F). Few androgen receptors were present in other amygdaloid nuclei, including the central $(\mathrm{Ce})$, lateral $(\mathrm{L})$, basolateral (BL), basomedial (BM), and anterior and posterolateral cortical nuclei (ACo and PLCo). Within Me, moderate numbers of androgen receptors were found in the anterior subdivision of $\mathrm{Me}$ (MeA, Fig. 4A,B), but receptors were heavily concentrated in the posterior subdivision (MeP, Fig. 4D-F). This distribution in Me is equivalent to that previously described for androgen and estrogen receptors in the hamster using steroid autoradiography ${ }^{12,19,49}$.

In BNST and MPOA (Fig. 5), androgen receptors were concentrated medially in the medial preoptic nucleus (MPN, Fig. 5C) and posteromedial BNST (BNSTpm, Fig. 5B-F), regions that receive substantial
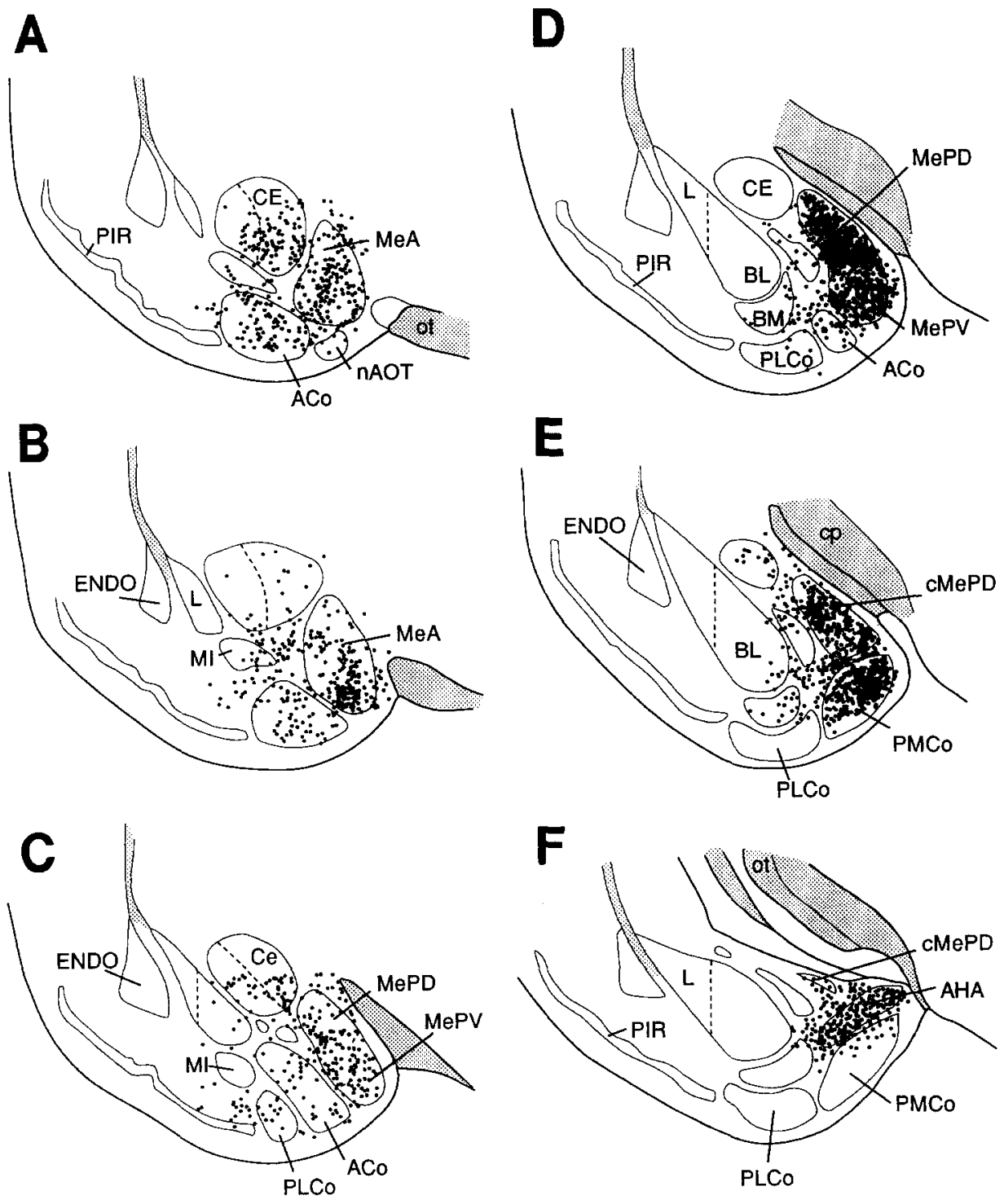

Fig. 4. Distribution of androgen receptor-immunoreactive neurons (dots) in coronal brain sections through the amygdala from rostral (A) to caudal $(F)$ in a representative male Syrian hamster. 
projections from MeP, PMCo, and $\mathrm{AHA}^{18,30}$. Receptors for androgens were less abundant laterally in the postero-intermediate BNST (BNSTpi) and MPOA, including the magnocellular MPN (MPNmag, Fig. 5D), areas that receive projections from $\mathrm{MeA}^{18}$. At the most rostral level (Fig. 5A), few androgen receptor-im- munoreactive nuclei were present in the anterior subdivisions of BNST (BNSTam and BNSTal), although the receptors were abundant in the lateral septum, dorsal to the BNST. Caudally, at the transition to the hypothalamus (Fig. 5F), the majority of androgen receptors surrounded the third ventricle.
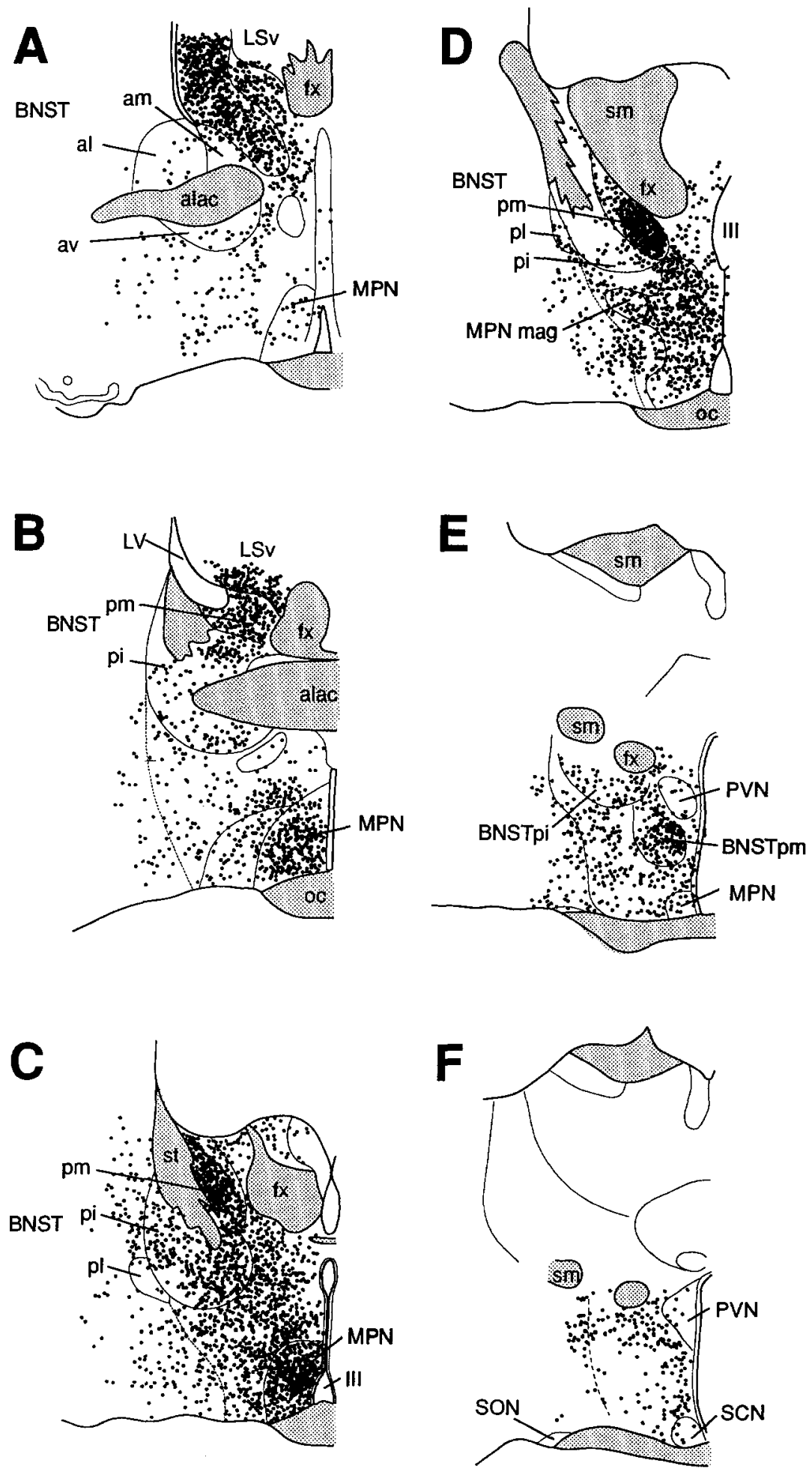

Fig. 5. Distribution of androgen receptor-immunoreactive neurons (dots) in coronal brain sections through the bed nucleus of the stria terminalis and medial preoptic area from rostral $(A)$ to caudal $(F)$ in a representative male Syrian hamster. 


\section{$c$-fos induction during mating}

Fig. 2 presents photomicrographs of Fos immunostaining from a representative unstimulated and mated hamster in the caudal portion of posterodorsal $\mathrm{Me}$ (cMePD), BNSTpm, and MPN. Figs. 6 and 7 illustrate the pattern of Fos immunoreactivity in the amygdala, BNST, and MPOA in unstimulated and mated hamsters; Fig. 8 compares the number of Fos-immunoreactive neurons in subdivisions of these three nuclei. With the Fos antiserum from Cambridge Research Biochemicals, basal c-fos expression in unstimulated males was low (see Figs. 2, 6, 7 (left) and 8); no consistent pattern of c-fos expression was observed in Me, BNST or MPOA, or in other parts of the brain. However, as described for the rat ${ }^{4,39}$ and for the hamster by Kollack and Newman ${ }^{23}$, mating dramatically increased the number of Fos-immunoreactive nuclei in the amygdala, BNST, and MPOA (Figs. 2, 6, 7 (right) and 8).

\section{CONTROL}
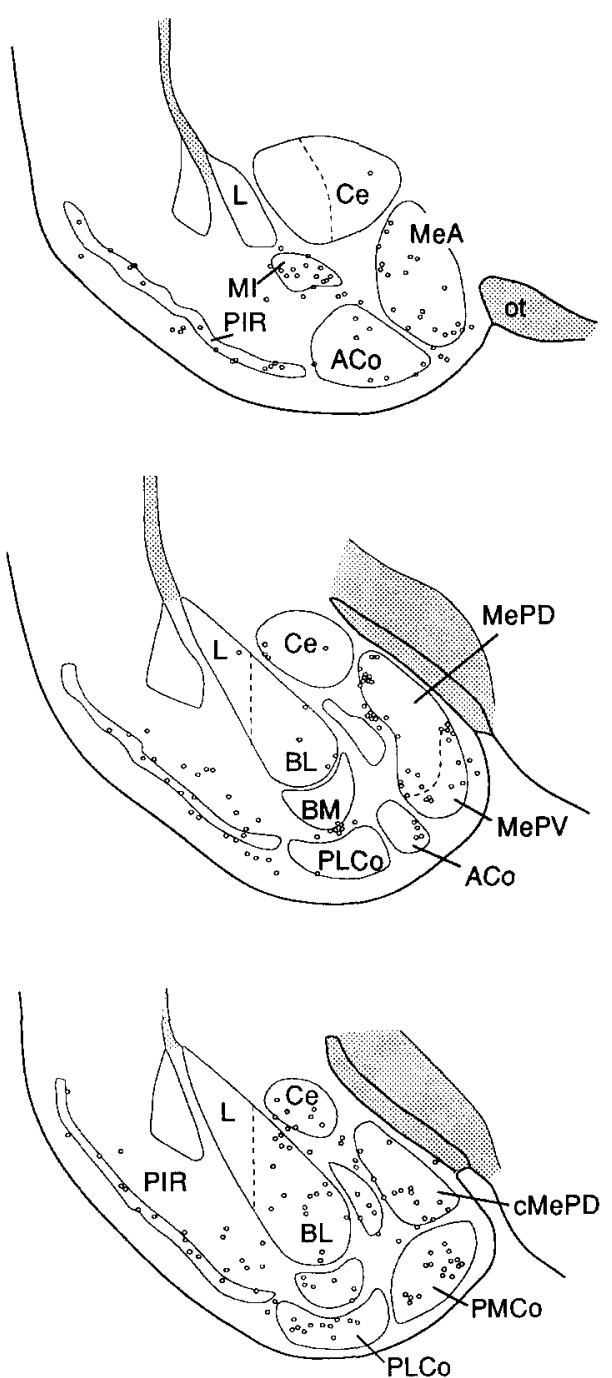

Fos immunoreactivity was increased in mated hamsters as compared to unstimulated males throughout the rostro-caudal extent of the corticomedial amygdala ( $P<0.05$; Figs. 6 and 8). Rostrally, c-fos expression after mating increased 3-5 times above basal values in ACo and MeA. At more caudal levels, mating induced a 5-12-fold increase in Fos-immunoreactive neurons in $\mathrm{MeP}$ and PMCo, regions that contain large numbers of androgen receptors. In particular, we observed two small clusters of Fos-immunoreactive nuclei in the caudal posterodorsal subdivision of Me (Fig. 2), as previously described by Kollack and Newman ${ }^{23}$. Mating also increased c-fos expression in PLCo and AHA $(P<$ 0.05 ), but had no discernible effect on c-fos expression in other regions of the amygdala, including $\mathrm{Ce}, \mathrm{L}, \mathrm{BL}$, and $\mathrm{BM}$.

Mating also significantly increased Fos immunoreactivity in BNST and MPOA $(P<0.05)$, as illustrated in

\section{MATED}
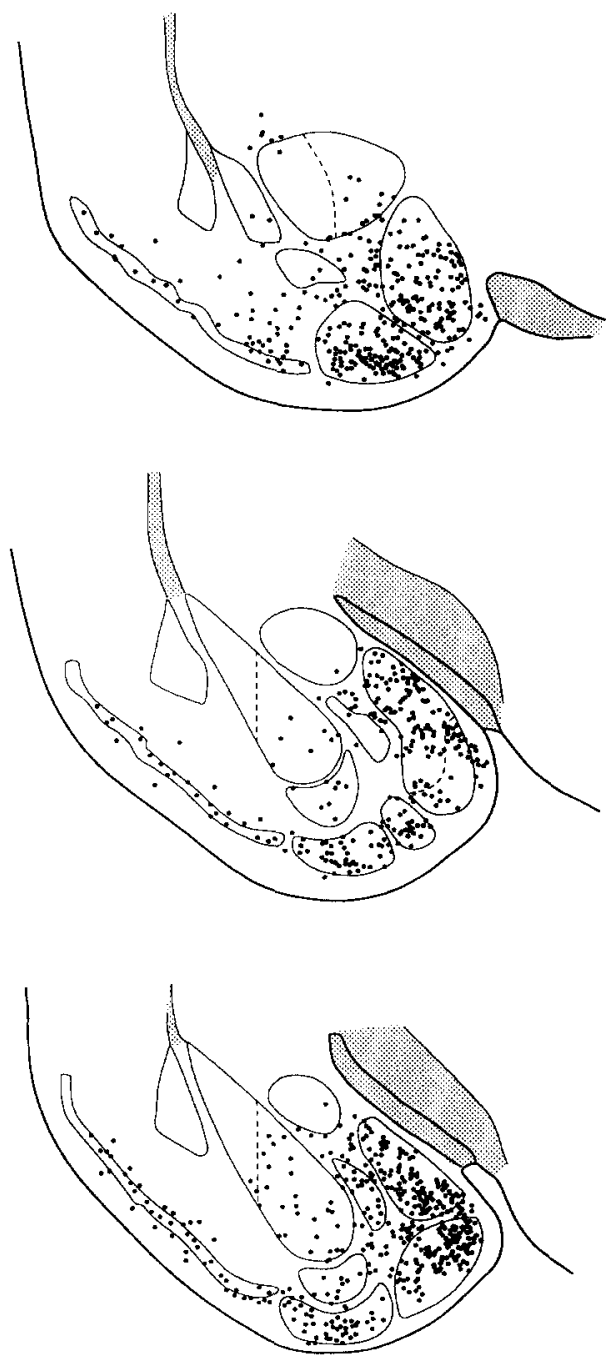

Fig. 6. Distribution of Fos-immunoreactive neurons (dots) in coronal brain sections through the amygdala from rostral to caudal in a representative control male (left) and in a male hamster allowed to mate for $30 \mathrm{~min}$ (right). 
Fig. 7. In the BNST, the greatest increase in c-fos expression was observed in BNSTpm, but significant increases in Fos immunoreactivity were also noted in the anteromedial, anteroventral, and postero-intermediate subdivisions. Copulation also caused a modest increase in c-Fos expression in $\operatorname{LSv}(P<0.05)$, immediately dorsal to BNSTam. In the MPOA, mating induced a significant increase in c-fos expression in both rostral and caudal MPN, areas that contain large numbers of androgen receptors. A striking increase in Fos immunoreactivity also occured in the MPNmag (Fig. 7,
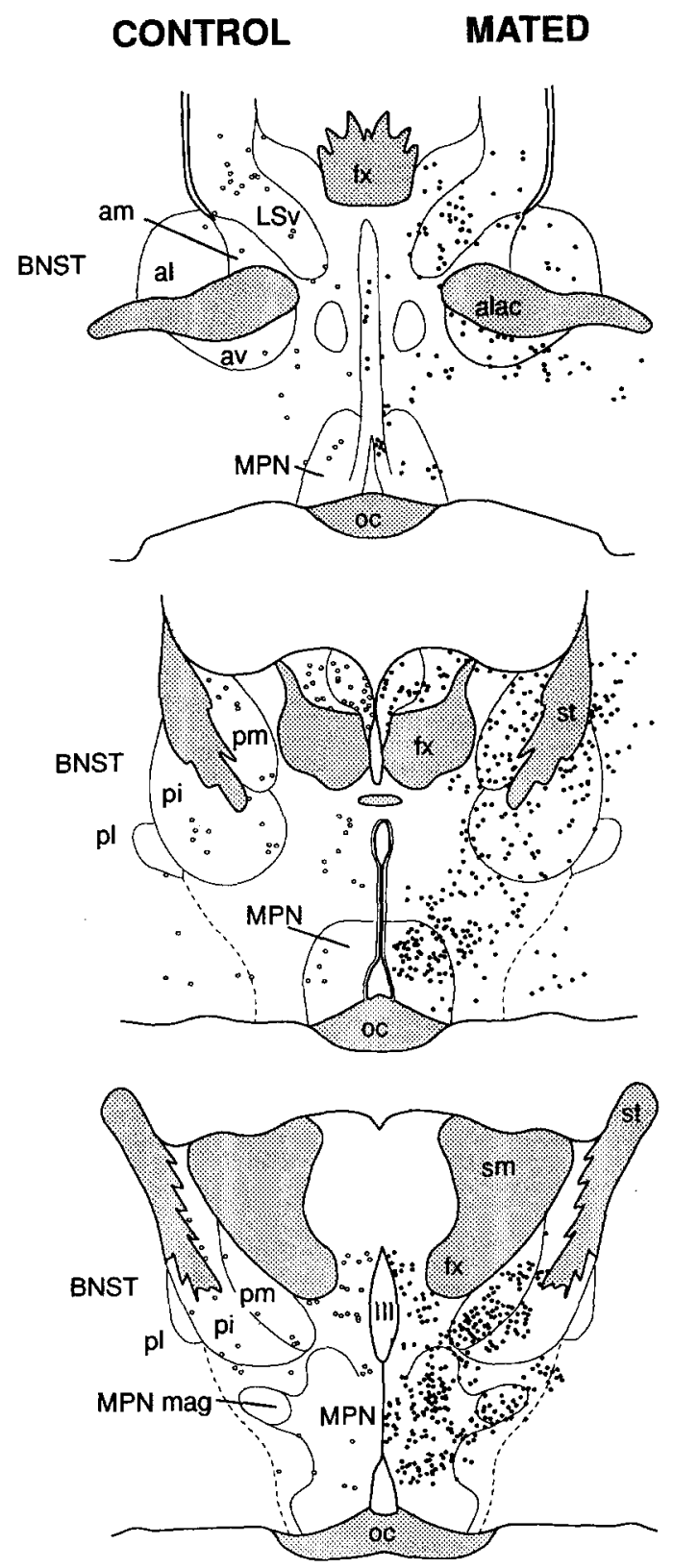

Fig. 7. Distribution of Fos-immunoreactive neurons (dots) in coronal brain sections through the BNST and MPOA from rostral to caudal in a representative control male (left) and in a male hamster allowed to mate for $30 \mathrm{~min}$ (right).

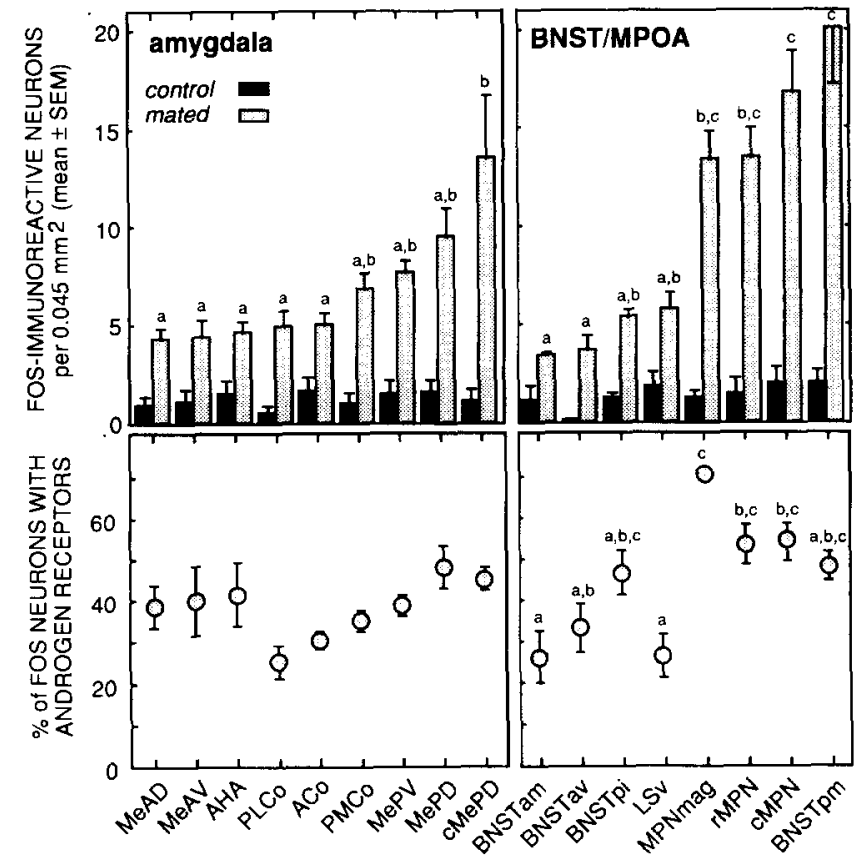

Fig. 8. Top: mean ( \pm S.E.M.) number of Fos-immunoreactive neurons in control ( $n=3$, dark bars) and mated ( $n=5$, light bars) hamsters through subdivisions of the amygdala (left) and BNST and MPOA (right). Bottom: percentage of Fos-immunoreactive neurons that contain androgen receptors in male Syrian hamsters allowed to mate for $30 \mathrm{~min}$.

bottom), as reported previously by Kollack and New$\operatorname{man}^{23}$.

\section{Co-localization of Fos and androgen receptors}

Fig. 3 presents photomicrographs of neurons in BNST that contain both androgen receptors and Fos; Fig. 8 illustrates the percentage of Fos-immunoreactive neurons that contained androgen receptors in subdivisions of the amygdala, BNST, and MPOA. In the amygdala, $25-48 \%$ of Fos-immunoreactive neurons were also immunolabelled for androgen receptors. Despite the differences in mating-induced c-fos expression and numbers of androgen receptor-positive neurons, there were no significant differences in the extent of co-localization in subnuclei of the amygdala $(P>$ 0.05 ). However, the percentage of Fos neurons containing androgen receptors varied in different subdivisions of the BNST and MPOA $(P<0.05)$. In the anterior portion of the BNST, which contains relatively few Fos-immunoreactive or androgen receptor-containing neurons, only $26-33 \%$ of Fos neurons contained androgen receptors. By contrast, in the posteromedial and postero-intermediate BNST, nearly half of the Fos-immunoreactive neurons co-localized with androgen receptors. Likewise, 53-54\% of Fos neurons in rostral and caudal MPN were androgen receptor-positive. However, the greatest degree of co-localization occurred in MPNmag. In this region, 70\% of Fos-im- 
munoreactive neurons also contained androgen receptors.

\section{DISCUSSION}

The present study demonstrates that specific populations of androgen receptor-containing neurons are activated during mating in the male Syrian hamster. Using the induction of c-fos as an index of neuronal activity ${ }^{19,31,41}$, copulation activates androgen receptorimmunoreactive neurons in the amygdala, particularly in the medial amygdaloid nucleus (Me), in the bed nucleus of the stria terminalis (BNST), and in the medial preoptic area (MPOA). Although it has long been recognized that steroid receptor-containing neurons are located in brain regions controlling sexual behavior, this study demonstrates that such neurons are stimulated during mating. The results of this study suggest that neurons containing androgen receptors within brain nuclei that relay chemosensory information to control sexual behavior may function in the control of copulation in this species.

\section{Androgen receptor immunoreactivity}

Previous studies in the hamster have identified androgen receptors using autoradiography for tritiated testosterone $^{49}$ or dihydrotestosterone ${ }^{12,49}$. With this technique, abundant, heavily labelled neurons are located in Me, AHA, BNST, MPOA, LSv, and in the ventromedial and arcuate nuclei of the hypothalamus. In general, the distribution of androgen receptor-immunoreactivity described in the present study is similar to that reported using autoradiography, although greater numbers of androgen receptor-positive cells are detected with immunocytochemistry. Autoradiography may be a relatively less sensitive technique than immunocytochemistry because it relies on the binding of labelled hormone to its receptor, and the subsequent deposition of silver grains on a photographic emulsion in quantities sufficient to enable unequivocal signal detection. Thus, we suggest that immunocytochemistry reveals additional neurons containing low levels of the androgen receptor that have not been detected by autoradiography.

Identification of the DNA sequence for the androgen receptor ${ }^{6,28}$ permitted the development of antibodies for immunocytochemical localization of androgen receptors in the brain and other tissues. Because it is still not feasible to purify the native receptor in sufficient quantities for innoculation, most androgen receptor antibodies have been generated with a synthetic peptide corresponding to a portion of the protein sequence. The antibody used in the present study is directed against the first 21 amino acids of the receptor protein. It appears to be specific for the androgen receptor, as evidenced by blocking studies. Furthermore, comparison of the amino acid sequences of the androgen and estrogen receptors ${ }^{6,22,28}$ suggests that this antibody should not cross-react with the estrogen receptor. Recent studies with other similar antibodies have described the distribution of androgen receptors in the brain of the rat ${ }^{42,47}$, monkey ${ }^{8}$, and quail ${ }^{2}$. The pattern of androgen receptor immunoreactivity and the number of immunoreactive neurons we have described in the hamster brain agrees well with that reported for other mammals. Furthermore, androgen receptor immunoreactivity is similar to that of the estrogen receptor. Both receptor proteins are located predominantly within the cell nucleus, and the distribution of labelled neurons overlaps considerably ${ }^{7,15,42,47}$. Using a combination of immunocytochemistry and autoradiography, androgen and estrogen receptors have been localized to the same neurons in the canary brain ${ }^{16}$. Whether androgen and estrogen receptors co-localize in the mammalian brain has not been determined.

\section{Fos immunoreactivity}

In recent years, the expression of c-fos, one of the family of immediate early genes (see ref. 10), has been used as a marker for activation of individual neurons following stimulation ${ }^{19,31,40}$. Fos protein can be detected immunocytochemically in cell nuclei in response to variety of neural (see ref. 32) and hormonally mediated signals ${ }^{5,20}$, including mating in the male hamster ${ }^{23}$ and rat $4,21,39$. The pattern of c-fos induction following male hamster sexual behavior in the present study resembled that described in a recent report from our laboratory ${ }^{23}$. These two studies used different Fos antisera, which could account for the differences in basal c-fos expression in control males. However, the location of Fos-immunoreactive nuclei in Me, BNST, and MPOA, including the activation of two small cell groups in caudal MePD, was strikingly similar.

Previously, the functional importance of different brain areas was inferred from lesion studies; expression of c-fos permits identification of individual activated neurons, which can then be further characterized in terms of connections, transmitter production, or receptors. Lesions centered in BNSTpm and MPN, regions that contain the largest number of mating-induced Fos-immunoreactive neurons, severely impair chemoinvestigation and mating behavior ${ }^{37}$. This concordance between c-fos induction and behavioral deficits induced by selective brain lesions supports the use of Fos as a tool to identify functionally relevant neural pathways. 
However, in the amygdala, there is some disparity between areas of marked c-fos induction and lesions that reduce mating. Although mating induces c-fos throughout Me, the greatest concentration of Fos-immunoreactive neurons is in MeP. By contrast, lesion studies suggest that the anterior subdivision of $\mathrm{Me}$ is critical for mating. Lesions of MeA eliminate copulation $^{25}$, whereas lesions of MeP reduce chemoinvestigation and lengthen the time to first ejaculation ${ }^{26}$. This difference illustrates one of the potential difficulties in interpreting the significance of c-fos activation. Induction of c-fos does not discriminate those neurons whose activation is essential for the expression of copulatory behavior from those activated merely as a consequence of the behavior. Thus, the large number of Fos-immunoreactive neurons in MeP may be a function of the amount and type of stimulation received, rather than the importance of that stimulation to mating behavior. In this regard, MeA contains only moderate numbers of steroid receptor-containing neurons, in contrast to the marked accumulation in MeP. Because MeP contains both a large number of androgen receptor-containing neurons and receives indirect olfactory and vomeronasal input via projections from $\mathrm{MeA}^{18,25}$, neurons in this region have the potential to receive substantial stimulation from chemosensory and hormonal signals during mating. Thus, the dramatic activation of c-fos in MeP may reflect the presence of multiple stimulatory inputs to this area rather than the functional importance of such stimulation.

\section{Co-localization of Fos and androgen receptors}

Results of the present study demonstrate that a sub-population of androgen receptor-containing neurons are activated during mating in the male hamster. However, mating is a complex behavior, and we do not know which specific aspects of copulation account for c-fos expression. Exposure to female hamster vaginal secretion alone can induce $c$-fos ${ }^{14}$, in a pattern similar to that observed after the full copulatory sequence. Mating also increases serum testosterone concentrations ${ }^{29}$, and gonadal steroids are known to increase Fos in the brain ${ }^{5,20}$. At the present time, we do not know if the activation of steroid receptor-containing neurons is a result of neural or hormonal stimulation. Certainly, the mere binding of androgen to its receptor is not sufficient to induce c-fos. If that were so, secretion of gonadal steroids would activate the entire complement of steroid receptor neurons in the brain. Instead, only a small fraction of androgen receptor-containing neurons in the amygdala, BNST, and MPOA contained Fos protein. This suggests that c-fos expression reflects a more potent activation of that neuron during copula- tion. It is important to note that although we have not yet determined if c-fos is expressed in estrogen receptor-positive neurons after mating, it is likely that the pattern of co-localization would be similar to that of androgen receptors. This is based upon the overlapping distributions of androgen and estrogen receptor neurons ${ }^{9,43,44,46,49}$, and involvement of estrogens in mating behavior in the male ${ }^{17,27,36,48}$.

In most subdivisions of the amygdala, BNST, and MPOA that demonstrate significant increases in Fos immunoreactivity during mating, subnuclei that contained larger numbers of androgen receptors and Fosimmunoreactive neurons also tended to show greater co-localization. Two notable exceptions warrant further consideration. Despite the striking accumulation of steroid receptors in the ventrolateral septum, relatively few Fos-immunoreactive neurons in that area contained androgen receptors. However, LSv is not considered critical for mating. Instead, it is associated with grooming behavior, aggression, and scent-marking (see ref. 45). Thus, the activation of neurons in this region may be due to some behavior that occurs during mating which is not dependent upon hormonal stimulation. In contrast to LSv, the MPNmag contains relatively fewer androgen receptor-containing neurons than adjacent medial structures, but androgen receptor-containing neurons in this region demonstrated the highest degree of activation. Lesions centered around MPNmag cause severe reductions in mounts, intromissions, and ejaculations ${ }^{37}$, suggesting that this nucleus is important for copulation. Furthermore, central implants of testosterone into the preoptic area are sufficient to restore mounting and intromissions in castrate males ${ }^{27}$, indicating that the gonadal steroid receptors in this region are critical for mating behavior. Nonetheless, it is unlikely that neurons in MPNmag maintain the entire complement of copulatory behaviors. The activation of androgen receptor-containing neurons in subnuclei throughout the mating behavior pathway in the male Syrian hamster suggests that copulation is not solely dependent upon a single group of steroid-responsive neurons. Instead, it seems probable that different populations of androgen receptor-containing neurons throughout the limbic system maintain steroid-dependent neural elements that contribute to the complex control of mating behavior in this species.

Acknowledgements. We thank Dr. Gail S. Prins of the University of Illinois-Chicago for the androgen receptor antiserum, Ms. Lorita Dudus and Ms. R. Kaye Brabec of the Reproductive Endocrinology Program Morphology Core Facility (P30-HD-18258) for assistance with tissue processing, and Mr. Stephen E. Asmus and Ms. Sara S. Kollack for their critical evaluation of this manuscript. This work supported by research and training grants from the NIH (NS-20629, HD-07514). 


\section{REFERENCES}

I Abe, H., Rusak, B., Robertson, H.A., Photic induction of Fos protein in the suprachiasmatic nucleus is inhibited by the NMDA receptor antagonist MK-801, Neurosci. Lett., 127 (1991) 9-12.

2 Balthazart, J., Foidart, A., Wilson, E.M. and Ball, G.F., Immunocytochemical localization of androgen receptors in the male songbird and quail brain, J. Comp. Neurol., 317 (1992) 407-420.

3 Baum, M.J., Neuroendocrinology of sexual behavior in the male. In J.B. Becker, S.M. Breedlove, D. Crews (Eds.), Behavioral Endocrinology, MIT Press, MA, 1992, pp. 97-130.

4 Baum, M.J. and Everitt, B.J., Immediate-early genes induced following sexual behavior in male rats: differential expression of c-fos in limbic structures, Soc. Neurosci. Abstr., 17 (1991) 1059.

5 Cattaneo, E. and Maggi, A., c-fos induction by estrogen in specific rat brain areas, Eur. J. Pharm., 188 (1990) 153-159.

6 Chang, C., Kokontis, J., Liao, S., Structural analysis of complementary DNA and amino acid sequences of human and rat androgen receptors, Proc. Natl. Acad. Sci. USA, 85 (1988) 72117215 .

7 Cintra, A., Fuxe, K., Harfstrand, A., Agnati, L.F., Miller, L.S., Greene, J.L., Gustafsson, J.-A., On the cellular localization and distribution of estrogen receptors in the rat tel- and diencephalon using monoclonal antibodies to human estrogen receptors, Neurochem. Int., 8 (1986) 587-595.

8 Clancy, A.N., Bonsall, R.W., Michael, R.P., Immunohistochemical labeling of androgen receptors in the brain of rat and monkey, Life Sci., 50 (1992) 409--417.

9 Commins, D. and Yahr, P., Autoradiographic localization of estrogen and androgen receptors in the sexually dimorphic area and other regions of the gerbil brain, J. Comp. Neurol., 231 (1985) 473-489.

10 Curran, T., Rauscher III, F.J., Cohen, D.R., Franza Jr., B.R., Beyond the second messenger: oncogenes and transcription factors, Cold Spring Harbor Symp. Quant. Biol., 53 (1988) 769-777.

11 Devor, M., Components of mating dissociated by lateral olfactory tract transections in male hamsters, Brain Res., 64 (1973) 437-441.

12 Doherty, P.C. and Sheridan, P.J., Uptake and retention of androgen in neurons of the brain of the male Syrian hamster, Brain Res., 219 (1981) 327-334.

13 Dudley, C.A., Rajendren, G. and Moss, R.L., Activation of the accessory olfactory system in the female rat by exposure to male-soiled bedding and repeated matings, Soc. Neurosci. Abstr., 17 (1991) 500.

14 Fiber, J.M. and Swann, J.M., Female hamster vaginal secretion stimulates $\mathrm{c}$-fos expression in the vomeronasal and olfactory mating behavior pathways in the male golden hamster, Soc Neurosci. Abstr., 17 (1991) 1060.

15 Furlow, J.D., Ahrens, H., Mueller, G.C. and Gorski, J., Antisera to a synthetic peptide recognize native and denatured rat estrogen receptors, Endocrinology, 127 (1990) 1028-1032.

$16 \mathrm{Gahr}, \mathrm{M}$., Localization of androgen receptors and estrogen receptors in the same cells of the songbird brain, Proc. Natl. Acad. Sci. USA, 87 (1990) 9445-9448.

17 Gomez, D.M. and Newman, S.W., Medial nucleus of the amygdala in the Syrian hamster: a quantitative Golgi analysis of gonadal hormone regulation of neuronal morphology, Anat. Rec., 231 (1991) 498-509.

18 Gomez, D.M. and Newman, S.W., Differential projections of the anterior and posterior regions of the medial amygdaloid nucleus in the Syrian hamster, J. Comp. Neurol., 317 (1992) 195-218.

19 Hunt, S.P., Pini, A. and Evan, G., Induction of c-fos-like protein in rat brain in spinal cord neurons following sensory stimulation, Nature, 328 (1987) 632-634.

20 Insel, T.R., Regional induction of c-fos-like protein in rat brain after estradiol administration, Endocrinology, 126 (1990) 18491853.

21 Insel, T.R. and Witt, D.M., Activation of c-fos-like protein in PVN oxytocin cells during male sexual behavior, Soc. Neurosci. Abstr., 17 (1991) 1415.

22 Koike, S., Sakai, M., Muramatsu, M., Molecular cloning and characterization of rat estrogen receptor cDNA, Nucleic Acids Res., 15 (1987) 2499-2513.

23 Kollack, S.S. and Newman, S.W., Mating behavior induces selective expression of fos protein within the chemosensory pathways of the male Syrian hamster brain, Neurosci. Lett., in press.

24 Krieger, M.S., Morrell, J.I. and Pfaff, D.W., Autoradiographic localization of estradiol-concentrating cells in the female hamster brain, Neuroendocrinology, 22 (1976) 193-205.

25 Lehman, M.N. and Winans, S.S., Vomeronasal and olfactory pathways to the amygdala controlling male hamster sexual behavior: Autoradiographic and behavioral analyses, Brain Res., 240 (1982) 27-41.

26 Lehman, M.N., Powers, J.B. and Winans, S.S., Stria terminalis lesions alter the temporal pattern of copulatory behavior in the male golden hamster, Behav. Brain Res., 8 (1983) 109-128.

27 Lisk, R.D. and Bezier, J.L., Intrahypothalamic hormone implantation and activation of sexual behavior in the male hamster, Neuroendocrinology, 30 (1980) 220-227.

28 Lubahn, D., Joseph, D., Sullivan, P., Willard, H., French, F., Wilson, E., Cloning of human androgen receptor complementary DNA and localization to the X chromosome, Science, 240 (1988) $327-330$

29 Macrides, F., Bartke, A., Fernandez, F., D'Angelo, W., Effects of exposure to vaginal odor and receptive females on plasma testosterone in the male hamster, Neuroendocrinology, 15 (1974) 355364.

30 Maragos, W.F., Newman, S.W., Lehman, M.N. and Powers, J.B., Neurons of origin and fiber trajectory of amygdalofugal projections to the medial preoptic area in Syrian hamsters, J. Comp. Neurol., 280 (1989) 59-71.

31 Morgan, J.I., Cohen, D.R., Hempstead, J.L., Curran, T., Mapping patterns of c-fos expression in the central nervous system after seizure, Science, 237 (1987) 192-197.

32 Morgan, J.I. and Curran, T., Stimulus-transcription coupling in the nervous system: involvement of the inducible proto-oncogenes fos and jun, Annu. Rev. Neurosci, 14 (1991) 421-451.

33 Morin, L. and Zucker, I., Photoperiodic regulation of copulatory behavior in the male hamster, J. Endocrinol, 77 (1978) 249-258.

34 Murphy, M.R. and Schneider, G.E., Olfactory bulb removal eliminates mating behavior in the male golden hamster, Science, 167 (1970) 302-304.

35 Platt, J.L. and Michael, A.F., Analysis of renal cell populations using monoclonal antibodies, Uremia Invest., 8 (1983) 203-213.

36 Powers, J.B., Bergondy, M.L. and Matochik, J.A., Male hamster sociosexual behaviors: effects of testosterone and its metabolites, Physiol. Behal., 35 (1985) 607-616.

37 Powers, J.B., Newman, S.W. and Bergondy, M.L., MPOA and BNST lesions in male Syrian hamsters: differential effects on copulatory and chemoinvestigatory behaviors, Behav. Brain Res., 23 (1987) 181-195.

38 Prins, G.S., Birch, L., Greene, G.L., Androgen receptor localization in different cell types of the adult rat prostate, Endocrinology, 129 (1991) 3187-3199.

39 Robertson, G.S., Pfaus, J.G., Atkinson, L.J., Matsumura, H., Phillips, A.G. and Fibiger, H.C., Sexual behavior increases c-fos expression in the forebrain of the male rat, Brain Res., 564 (1991) 352-357.

40 Sachs, B.D. and Meisel, R.L., The physiology of male sexual behavior. In E. Knobil and J.D. Neill (Eds.), The Physiology of Reproduction, Raven Press, NY, 1988, pp. 1393-1486.

41 Sagar, S.M., Sharp, F.R. and Curran, T., Expression of c-fos protein in brain: metabolic mapping at the cellular level, Science, 240 (1988) 1328-1331.

42 Sar, M., Lubahn, D.B., French, F.S. and Wilson, E.M., Immunohistochemical localization of the androgen receptor in rat and human tissues, Endocrinology, 127 (1990) 3180-3184.

$43 \mathrm{Sar}, \mathrm{M}$. and Stumpf, W.E., Autoradiographic localization of radioactivity in the rat brain after the injection of $1,2-3 \mathrm{H}$ testosterone, Endocrinology, 92 (1973) 251-256.

44 Sheridan, P.J., Localization of androgen- and estrogen-concentrating neurons in the diencephalon and telencephalon of the mouse, Endocrinology, 103 (1978) 1328-1334. 
45 Siegel, H.I., Aggressive behavior. In H.I. Siegel (Ed.), The Hamster: Reproduction and Behavior, Plenum Press, NY, 1985, pp 261-288.

46 Simerly, R.C., Chang, C., Muramatsu, M. and Swanson, L.W., Distribution of androgen and estrogen receptor mRNA-containing cells in the rat brain: an in situ hybridization study, J. Comp. Neurol., 294 (1990) 76-95.

47 Takeda, H. and Chang, C., Immunohistochemical and in-situ hybridization analysis of androgen receptor expression during development of the mouse prostate gland, $J$. Endocrinology, 129 (1991) 83-89.
48 Whalen, R.E. and DeBold, J.F., Comparative effectiveness of testosterone, androstenedione and dihydrotestosterone in maintaining mating behavior in the castrated male hamster, Endocrinology, 95 (1974) 1674-1679.

49 Wood, R.I., Brabec, R.K., Swann, J.M. and Newman, S.W., Androgen and estrogen receptor-containing neurons in chemosensory pathways of the male Syrian hamster brain. Brain Res., 596 (1992) 89-98. 